\title{
Invasive Ductular Reaction Operates Hepatobiliary Junctions upon Hepatocellular Injury in Rodents and Humans
}

Laure-Alix Clerbaux, ${ }^{*}$ Rita Manco, ${ }^{*}$ Noémi Van Hul, ${ }^{\dagger}$ Caroline Bouzin, ${ }^{\ddagger}$ Amedeo Sciarra, ${ }^{\S}$ Christine Sempoux, ${ }^{\S}$ Neil D. Theise, ${ }^{\S}$ and Isabelle A. Leclercq*

From the Laboratory of Gastroenterology* and the Imaging Platform, ${ }^{\ddagger}$ Institute of clinical and Experimental Research, Université Catholique de Louvain, Brussels, Belgium; the Department of Biosciences and Nutrition, ${ }^{\dagger}$ Karolinska Institute, Stockholm, Sweden; the Service of Clinical Pathology, ${ }^{\S}$ Lausanne University Hospital, Institute of Pathology, Lausanne, Switzerland; and the Department of Pathology, "New York University School of Medicine, New York, New York

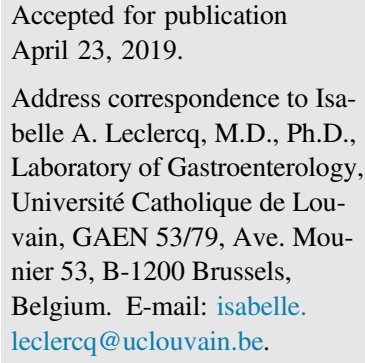

\begin{abstract}
Ductular reaction (DR) is observed in virtually all liver diseases in both humans and rodents. Depending on the injury, DR is confined within the periportal area or invades the parenchyma. On severe hepatocellular injury, invasive DR has been proposed to arise for supplying the liver with new hepatocytes. However, experimental data evidenced that DR contribution to hepatocyte repopulation is at the most modest, unless replicative capacity of hepatocytes is abrogated. Herein, we proposed that invasive DR could contribute to operating hepatobiliary junctions on hepatocellular injury. The choline-deficient ethionine-supplemented mouse model of hepatocellular injury and human liver samples were used to evaluate the hepatobiliary junctional role of the invasive form of DR. Choline-deficient ethioninesupplemented-induced DR expanded as biliary epithelium into the lobule and established new junctions with the canaliculi. By contrast, no new ductular-canalicular junctions were observed in mouse models of biliary obstructive injury exhibiting noninvasive DR. Similarly, in humans, an increased number of hepatobiliary junctions were observed in hepatocellular diseases (viral, drug induced, or metabolic) in which DR invaded the lobule but not in biliary diseases (obstruction or cholangitis) in which DR was contained within the portal mesenchyme. In conclusion, our data in rodents and humans support that invasive DR plays a hepatobiliary junctional role to maintain structural continuity between hepatocytes and ducts in disorders affecting hepatocytes. (Am J Pathol 2019, 189: 1569-1581; https://doi.org/10.1016/j.ajpath.2019.04.011)
\end{abstract}

The biliary tree is an arborizing network of conduits that drains bile secreted by hepatocytes to the gut. Bile secretion is an active and tightly regulated process resulting in extrusion of biliary components at the apical pole of hepatocytes into a space sealed by tight junctions between adjacent hepatocytes, the canaliculus. Coordinated contractions of the pericanalicular microfilaments drain bile downstream to bile ductules delineated by cholangiocytes enclosed in the portal mesenchyme. The canal of Hering $(\mathrm{CoH})$, a transitional structure formed by the apical poles of hepatocytes in the periportal region and by cholangiocytes of the most proximal extremities of the bile ductules, represents the anatomic interface between the canaliculi and the ducts. ${ }^{1}$ Small ductules converge to form larger ducts, then carry the bile to the gallbladder and the gut. ${ }^{2}$ The morphology and functional properties of cholangiocytes vary gradually along the proximal to distal axis. ${ }^{3-5}$ Cholestasis may be caused by a large variety of structural or functional insults that can occur at any level between the hepatocytes and the ampulla of Vater, which results in

Supported by a Fund for Scientific Medical Research (FRS-FNRS, Belgium) grant PDR T.1067.14 (I.A.L.) and the Belgian Federal Science Policy Office (Interuniversity Attraction Poles Program) grant Network P7/ 83-HEPRO2 (I.A.L.).

Disclosures: None declared. 
decreased bile secretion or flux. ${ }^{6,7}$ Cholestasis accordingly encompasses a broad variety of liver pathologies, as the three anatomic domains of the biliary tract (namely, bile canaliculi, intralobular bile ducts, and large bile ducts) respond morphologically and functionally differently to injury. ${ }^{8}$ However, a hallmark of chronic liver diseases, including cholestatic disorders, is the appearance of ductular reaction (DR). ${ }^{9}$ DR morphology may range from structures formed by cuboid cells, delineating a clear lumen and constrained within the portal mesenchyme, to elongated cells with a migratory phenotype, invading the parenchyma. This diversity of DR pattern, observed in both humans and rodent models, has been related to the nature and cell compartment being injured. ${ }^{9-13}$ Proliferation of pseudoducts is typically seen on cholangiocellular diseases, such as in primary biliary cholangitis or primary sclerosing cholangitis. In experimental animals, bile duct ligation (BDL) or diethoxycarbonyl-1,4-dihydrocollidine (DDC) diet cause a type of DR that has been demonstrated to represent the twodimensional proliferative rearrangement of the biliary epithelium. ${ }^{10,14}$ In hepatocellular diseases, DR manifests as the invasion of the parenchyma by elongated cells expressing biliary markers. This is seen in viral hepatitis $\mathrm{C}$ or autoimmune disease in humans or in the choline-deficient ethionine-supplemented (CDE) model in rodents. ${ }^{12}$ Whether DR is ever responsible for parenchymal reconstitution remains controversial. Parenchymal reconstitution from DR has been suggested in severe acute injury in human livers ${ }^{15}$ and in advanced-stage chronic human disease. ${ }^{16,17}$ Some studies in rodents ${ }^{18,19}$ and in zebrafish ${ }^{20}$ convincingly demonstrated significant parenchymal reconstitution from the DR compartment, specifically when proliferative capacity of hepatocytes is abrogated or in case of massive parenchymal injury. Singularly, when hepatocytes retain some replicative competence, DR contribution to hepatocyte repopulation is at the most modest, if not negligible. ${ }^{21-25}$ This has been well exemplified, by us and others, with the CDE model of florid and invasive DR. ${ }^{11,21,22,24-28}$ Instead of reflecting a lack of functional importance of CDEinduced DR, these results could suggest that the invasive form of DR may have physiological functions other than parenchymal reconstitution. Hepatocytes could accomplish regeneration in the unlined regions of parenchyma, whereas the DR compartment could be required to preserve or repair a canalicular-ductal morphologic link..$^{29,30}$

Herein, we show that CDE-induced DR expands into the parenchyma as biliary epithelium, which establishes de novo junctions with canaliculi. Reduction of CDE-induced DR extent significantly decreased the number of hepatobiliary junctions. By contrast, new ductular-canalicular junctions were not observed in the BDL or DDC models of biliary obstructive injury. In a similar manner, an increased number of hepatobiliary junctions in viral, drug-induced, or metabolic hepatocellular diseases in which DR invades the lobule, but not in biliary diseases (obstruction, primary biliary cholangitis, or primary sclerosing cholangitis) in which DR is contained within the portal mesenchyme was observed in humans. These findings support that the invasive form of DR connects with the canalicular system and operates hepatobiliary junctions after disorders affecting predominantly hepatocytes.

\section{Materials and Methods}

\section{Animals}

All animal experiments were performed with approval of the University Animal Welfare Committee (2012UCLMD026; 2016UCLMD003). Five-week-old male C57B1/6J mice (weight, $<18 \mathrm{~g}$ ), obtained from Janvier-Breeding Center (Le Genest St. Isle, France), were housed in a conventional facility after a 12-hour light/dark cycle. On 1 week of acclimatization, mice received either chow diet (control group) or a diet deficient in choline (MP Biomedicals, Irvine, CA), together with drinking water supplemented with $0.15 \%(w / v)$ ethionine (Sigma, Bornem, Belgium) during 3, 9, 14, or 21 days (CDE groups). To block Notch signaling, mice were treated with the $\gamma$-secretase inhibitor dibenzazepine (DBZ; Syncom BV, Groningen, the Netherlands) ${ }^{31}$ via i.p. daily injection for 14 days at a dose of $5 \mu \mathrm{mol} / \mathrm{kg}$ in combination with CDE treatment (CDE-DBZ group) or without CDE treatment (DBZ group). To mimic obstructive cholestasis, mice received a 3,5DDC-containing diet (137030; Sigma-Aldrich, St. Louis, MO) during 9 days, or BDL was performed by double ligation and section of the common bile duct. BDL mice were fed chow diet at all times and sacrificed 9 days after surgery. To identify DR-derived hepatocytes, mice expressing the $\mathrm{T} 2$ variant of tamoxifen-inducible cyclization recombinase estrogen receptor ligand binding domain $\left(\mathrm{CreER}^{\mathrm{T} 2}\right)$ under the control of the osteopontin promotor (osteopontin-iCreER ${ }^{\mathrm{T} 2}$ mice) crossed with Rosa26-yellow fluorescent protein (YFP) mice were used. Offspring were then injected with tamoxifen (T5648; Sigma) before CDE treatment, as previously described. ${ }^{22,32}$ After overnight fasting, mice were sacrificed and blood and liver samples were collected. Part of the liver was fixed in $4 \%$ formalin for histologic analyses. The remaining liver lobes were immediately snap frozen in liquid nitrogen and kept at $-80^{\circ} \mathrm{C}$ until use.

\section{Human Liver Biopsy Specimens}

Formalin-fixed, paraffin-embedded specimens of human liver biopsies $(n=20)$ were retrieved from the archives of the Institute of Pathology of Lausanne (Lausanne, Switzerland). Twelve patients had a predominant hepatocellular injury: nonalcoholic steatohepatitis ( $n=3$ ), drug-induced liver injury $(n=6)$, autoimmune hepatitis $(n=2)$, and viral hepatitis $(n=1)$. Eight patients had a biliary disease: primary biliary cholangitis $(n=3)$, primary sclerosing cholangitis $(n=3)$, and biliary obstruction $(n=2)$. The study was performed in accordance with the cantonal ethic committee recommendations and the Declaration of Helsinki. A synchronous double 
anti-cytokeratin 19 (CK19; ductular reaction, brown chromogen)-anti-CD-10 (hepatocyte canaliculi, red chromogen) immunohistochemical detection was performed on a fresh recut of the liver biopsy for each case (CK19: RCK108 clone from Dako-Agilent, Santa Clara, CA; and CD10: 56C6 clone from Novocastra Laboratories LDT, Newcastle upon Tyne, UK).

In these biopsies, when at least one CK19-CD10 junction around a portal tract $(\mathrm{PT})$ was observed $>80 \mu \mathrm{m}$ from the border of the portal mesenchyma, the associated DR was classified as invasive; when junctions were observed between 20 and $80 \mu \mathrm{m}$, DR was categorized as minimally invasive; and when junctions were seen $<20 \mu \mathrm{m}$ or within the portal mesenchyma, DR was classified as noninvasive.

\section{Immunohistochemistry and Immunofluorescence}

Mouse liver sections were incubated with primary antibodies against CK19 (dilution 1:10; Developmental Studies Hybridoma Bank, University of Iowa, Iowa City, IA), then with a horseradish peroxidase-conjugated secondary antibody and binding revealed with 3,3'-diaminobenzidine. Diaminobenzidine-stained sections were digitalized with a SCN400 slide scanner (Leica, Wetzlar, Germany). On CK19stained slides, the stained area was measured using Tissue IA software version 2.0.04 (Leica Biosystems, Dublin, Ireland). For immunofluorescence labeling, liver sections were exposed to antibodies directed against CK19 (dilution 1:10; Developmental Studies Hybridoma Bank), mucin-1 (dilution 1:200; MUC-1 Ab-5; NeoMarkers, Fremont, CA), laminin (dilution 1:50; ab11575; Abcam, Cambridge, UK), acetylated $\alpha$-tubulin (dilution 1:1000; T6793; Sigma), carcinoembryonic antigen-related cell adhesion molecule (ceacam)-1 (dilution 1:500; LS-C106710; LifeSpan Biosciences, Seattle, WA), and YFP (dilution 1:250; ab6673; Abcam). Secondary antibodies were anti-rat IgG, anti-goat IgG, or anti-rabbit IgG, combined to AlexaFluor 594, AlexaFluor 488, or AlexaFluor 647 (dilution 1:1000; Invitrogen, Merelbeke, Belgium), as appropriate. For mucin-1 immunodetection, sections were incubated with anti-hamster IgG (dilution 1:250; 127-065160; Jackson ImmunoResearch, Ely, UK) and then with AlexaFluor 488 (1:1000; Invitrogen). Hoechst (dilution $1: 10,000)$ was used to reveal the nuclei. After double immunofluorescence of ceacam-1 and mucin-1, optical sections were generated by structured illumination using an AxioImager microscope (Carl Zeiss Company, Oberkochen, Germany) and then analyzed using the image analysis tool Author version 6.0.0 (Visiopharm, Hørsholm, Denmark). Portal fields were delineated manually; then, a concentric area of $170 \mu \mathrm{m}$ was automatically extended by the Visiopharm software. The junctions between mucin-1 (green) and ceacam-1 (red) were assessed manually, and the shortest distance between each junction and the portal vein was measured by the Visiopharm software. For Z-stack imaging, liver slides (vibratome; $100 \mu \mathrm{m}$ thick) were exposed under agitation for 2 days at $4{ }^{\circ} \mathrm{C}$ first to primary antibody against mucin- 1 and then for 2 days at $4{ }^{\circ} \mathrm{C}$ to primary antibody against ceacam- 1 , followed by 2 days at $4^{\circ} \mathrm{C}$ with secondary antibody anti-hamster $\mathrm{IgG}$, and finally with a mixture of AlexaFluor 488, secondary antibody anti-mouse IgG combined to AlexaFluor 594, and Hoechst. Liver sections were examined with a Zeiss LSM510 confocal microscope.

\section{RNA Extraction and Real-Time Quantitative RT-PCR}

Total RNA was extracted using TRIzol (Invitrogen). Quantitative real-time PCR was performed by $\mathrm{AB}$ StepOne Plus (Applied Biosystems, Foster City, CA) using SYBR Green PCR Master Mix (Applied Biosystems). Expression of $36 B 4$ was used as an internal standard. Results are expressed as fold expression relative to expression in the control (value set at 1) using the $\Delta \Delta \mathrm{Ct}$ method.

\section{Statistical Analysis}

All data are presented as means \pm SD or means \pm SEM when indicated, and were compared using the unpaired twotailed $t$-test or one-way analysis of variance.

\section{Results}

DR Invades the Lobule as Biliary Polarized Epithelium in CDE Livers

CDE-fed mice display a DR that progressively invades the hepatic lobule. ${ }^{33}$ In livers of mice controls or fed with CDE diet for 3 days, staining of the well-established biliary/DR marker CK19 was restricted to cholangiocytes of the bile ducts and single isolated cells around the PTs, corresponding to $\mathrm{CoH}$ (Figure 1). After 9 days of CDE, CK19 ${ }^{+}$DR expands outside the portal area; and after 21 days, DR number significantly increased as they invaded the hepatic lobule (Figure 1A). Mucin-1 is a glycoprotein produced by and lining the apical surface of cholangiocytes facing bile duct lumen in normal livers (Figure 1B). While on the basal side, cholangiocytes (but not hepatocytes) lie on a laminin basement membrane (Figure 1C). ${ }^{22}$ Like for cholangiocytes, mucin-1 staining was polarized at the apical pole of DR cells (Figure 1B), whereas laminin was located at their basal pole (Figure 1C). Cholangiocytes carry a primary cilium, a sensory organelle that protrudes from the apical pole into the duct lumen and detects changes in bile flow and composition. As in bile ducts, CDEinduced DR exhibited acetylated $\alpha$-tubulin-positive staining, aligning longitudinally along the lumen (Figure 1D). Cholangiocytes release bicarbonate, ${ }^{3}$ through activation of the secretin receptor (SR), the cystic fibrosis transmembrane conductance regulator (CFTR), and the chloride/bicarbonate anion exchanger 2 (AE2). Hepatic mRNA expression levels of $S R$ and CFTR (but not of AE2; data not shown) were significantly increased in 9- and 21-day CDE livers, when infiltrative DR was seen and positively correlated with CK19 mRNA hepatic expression (Figure 1, E and F). Altogether, these data 

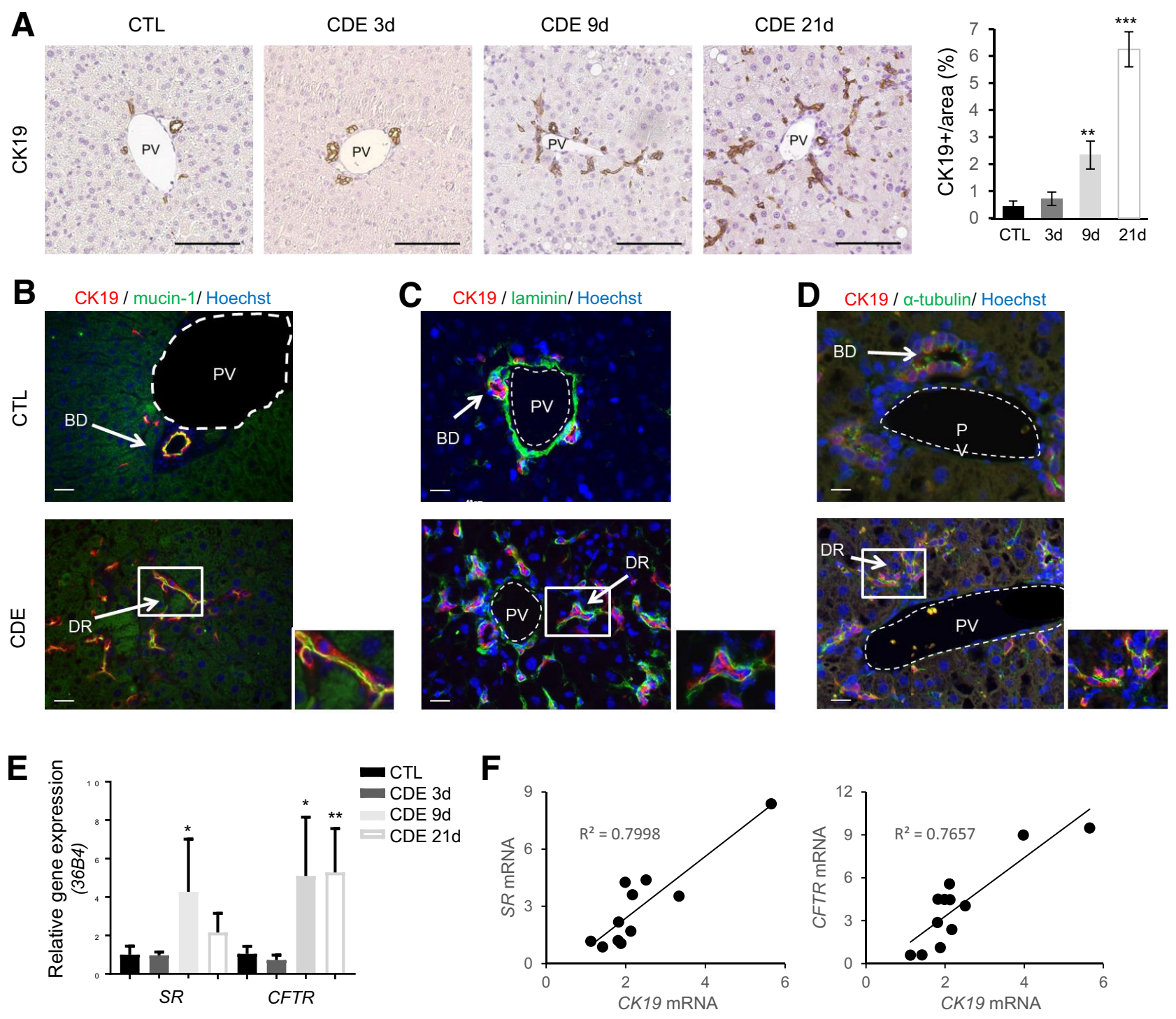

Figure 1 Ductular reaction (DR) expands as polarized biliary epithelium in choline-deficient ethionine-supplemented (CDE) livers. A: Liver sections from mice receiving chow diet [control (CTL)] or CDE diet for 3, 9, or 21 days (3d, 9d, or 21d) were stained with cytokeratin 19 (CK19). Morphometrical quantification of the area occupied by CK19 ${ }^{+}$cells in livers confirmed DR expansion in CDE livers. Significance was calculated compared with controls. B-D: Liver sections from CTLs and from mice receiving 9 days of CDE (CDE) were costained with CK19 (red) and mucin-1 (green; B), with CK19 (red) and laminin (green; C), and with CK19 (red) and acetylated $\alpha$-tubulin (green; D). Hoechst was used to stain the nuclei (blue). Higher magnifications of the boxed areas in the CDE livers are shown to the right. E: Hepatic mRNA expression levels of secretin receptor (SR) and cystic fibrosis transmembrane conductance regulator (CFTR) from mice fed a chow diet (black bars) or receiving 3, 9, or 21 days of CDE diet (gray bars). Values are expressed as mRNA arbitrary units compared with controls and normalized to 36B4 mRNA. F: Hepatic expression of SR and CFTR mRNA positively correlated with that of CK19 mRNA in CDE livers exhibiting invasive DR. Data are expressed as means \pm SEM $(\mathbf{A})$ or means $\pm \mathrm{SD}(\mathbf{E}) . n=6$ per group $(\mathbf{A}) ; n=5-7$ per group $(\mathbf{E}) ; n=11(\mathbf{F}) .{ }^{*} P<0.05,{ }^{*} P<0.01$, and ${ }^{* * *} P<0.001$ versus control. Scale bars: $100 \mu \mathrm{m}(\mathbf{A}) ; 20 \mu \mathrm{m}(\mathbf{B}-\mathbf{D})$. BD, bile duct; PV, portal vein.

support that DRs expand as polarized biliary epithelium expressing the machinery needed to sense and modify bile (flow).

\section{Invasive Biliary DR Establishes New Junctions with Intralobular Canaliculi in CDE Livers}

DR and bile ducts constitute together a continuous network in CDE livers. ${ }^{10,34}$ Whether these ductular ramifications emerging in the continuity of the biliary tree connect, on the other side, to the canalicular system has never been explored.
To visualize the ductular-canalicular junctions, double staining was performed with mucin-1 to label the apical pole of biliary/DR cells; and ceacam-1 was used for the hepatocyte canaliculi. ${ }^{22,35-37}$ The mucin-1-ceacam-1 junctions appeared as either continuous on the same plane or overlapping, depending on the angle of the two-dimensional (2D) analysis (Figure 2B). Between zero and two ductularcanalicular junctions were identified per PT in control livers (Figure 2B). As confirmed using tamoxifen-injected osteopontin-iCreER ${ }^{\mathrm{T} 2}$;Rosa26-YFP mice, in which biliary cells are readily identified by their YFP tag, ${ }^{22}$ mucin-1-expressing 

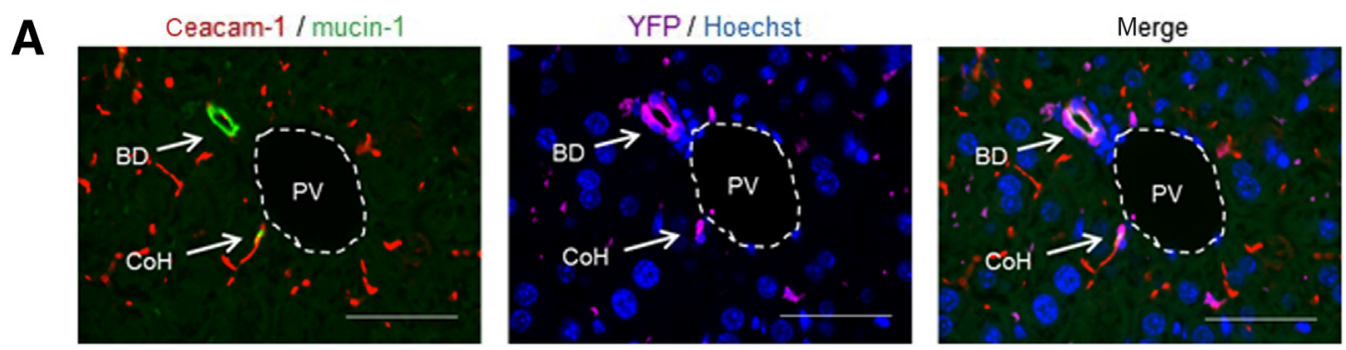

B
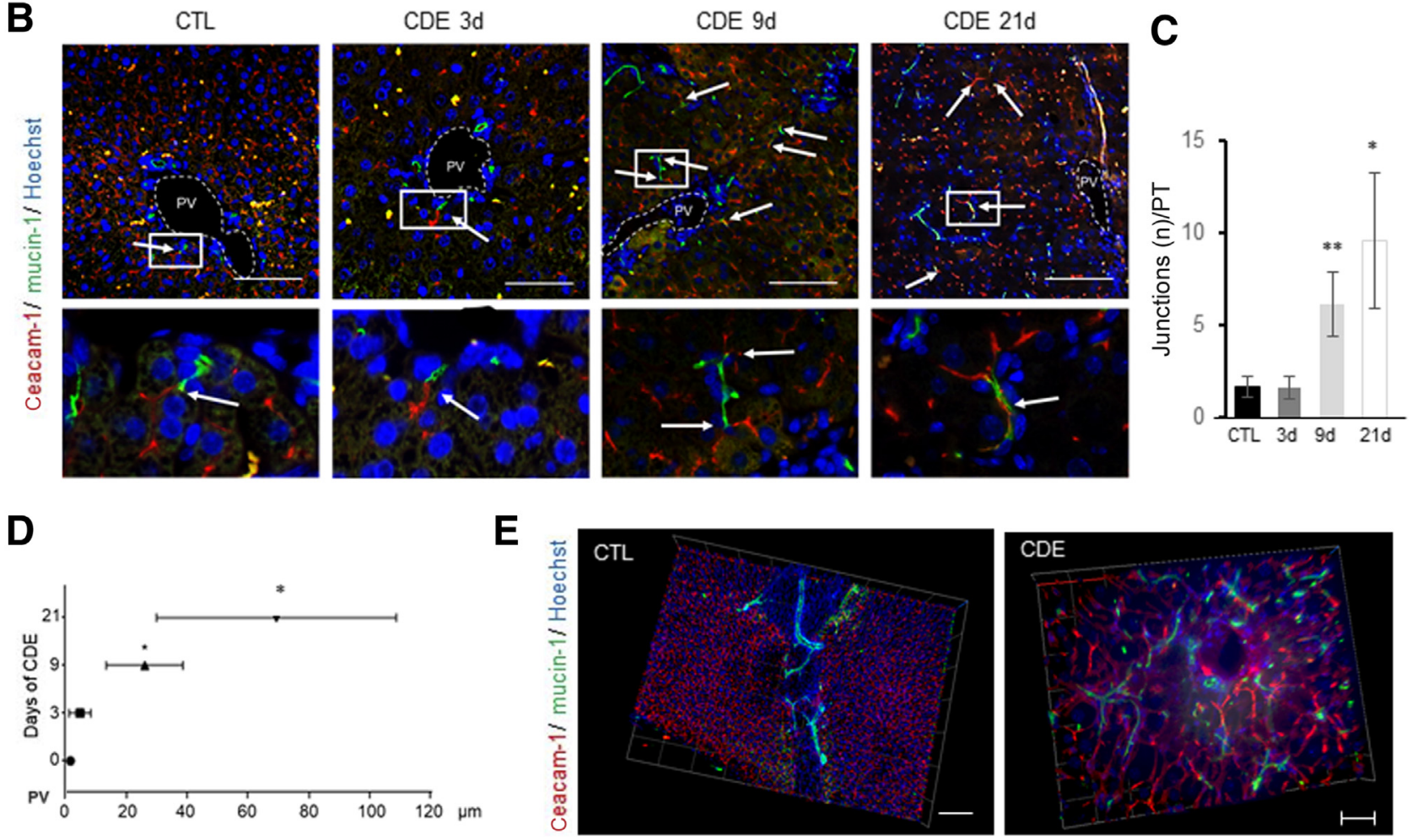

Figure 2 New duct-canaliculi junctions are established on choline-deficient ethionine-supplemented (CDE) hepatocellular injury. A: Liver sections from osteopontin-iCreER ${ }^{\top 2}$;Rosa26-YFP mice fed 9 days of CDE regimen (CDE) were costained with ceacam-1 (red), mucin-1 (green), and YFP (magenta). Hoechst was used to stain the nuclei (blue). B: Liver sections from mice receiving control diet (CTL) or CDE treatment for 3, 9, or 21 days (3d, 9d, or 21d, respectively) were costained with ceacam-1 (red), mucin-1 (green), and Hoechst (blue). Arrows indicate caecam-1/mucin-1 junctions. Boxed areas are shown at higher magnification below. $\mathbf{C}$ and $\mathbf{D}$ : These liver sections were used to quantify the number of junctions (C; arrows in $\mathbf{B}$ ) and to measure the distance between the junctions and the wall of the closest portal vein (PV; D). Significance was calculated compared with controls. E: Z-stack imaging of liver section (100 $\mu \mathrm{m}$ thick) from mice receiving a chow (CTL) or CDE diet for 9 days (CDE) stained with ceacam-1 (red), mucin-1 (green), and Hoechst (blue). Depth: $100 \mu \mathrm{m}$ (CTL) and 40 $\mu \mathrm{m}(\mathrm{CDE})$. Data are expressed as means $\pm \mathrm{SD}(\mathbf{C}$ and $\mathbf{D}) . n=3-5$ mice per group $(\mathbf{C}$ and $\mathbf{D}) .{ }^{\star} P<0.05,{ }^{* \star} P<0.01$ versus control. Scale bars: $50 \mu \mathrm{m}(\mathbf{A}) ; 100$ $\mu \mathrm{m}$ (B and $\mathbf{E}$, left panel); $40 \mu \mathrm{m}$ (E, right panel). BD, bile duct; $\mathrm{CoH}$, canal of Hering; PT, portal tract.

cells engaged in these junctions were isolated periportal biliary $\mathrm{YFP}^{+}$cells, corresponding to $\mathrm{CoH}$ and not the biliary cells forming the bile ducts (Figure 2A). Similar to controls, zero to two ductular-canalicular junctions were observed around each PT in 2D liver sections in mice fed CDE for 3 days (Figure 2, B and C). In contrast, in 9- and 21-day CDE livers, the number of mucin-ceacam junctions per PT increased markedly to threefold and fivefold, respectively (Figure 2C). In controls and 3-day CDE livers, ductularcanalicular junctions were located at the edge of the portal mesenchyme (Figure 2D), whereas in the 9- and 21-day CDE livers, the ductular-canalicular junctions were found inside the lobule, at a mean distance of 30 and $70 \mu \mathrm{m}$ from the portal vein, respectively (Figure 2D). Because the count of junctions can be underestimated on 2D slices, Z-stack imaging was performed. Z-stack imaging offered an elegant visualization of the biliary tree encompassing its canalicular part in control livers (Figure 2E) and clearly confirmed the higher number of junctions between the ductular and the canalicular network deep inside the parenchyma on CDE injury (Figure 2E and Supplemental Movie S1).

The point of transition between hepatocyte- and cholangiocyte-lined lumens implies the presence of a transitional polarized cell able to tightly interact with a hepatocyte on one side and with a cholangiocyte on the other side. To interrogate whether such a transitional cell emerges from the DR, the 
tamoxifen-injected osteopontin-iCreER ${ }^{\mathrm{T} 2}$;Rosa26-YFP mice were used as a genetic tool to trace approximately $90 \%$ of cholangiocytes. $^{22,37}$ On CDE diet, a large bulk of DR cells was $\mathrm{YFP}^{+}$and interestingly all of the mucin ${ }^{+}$cells engaged in a junction were $\mathrm{YFP}^{+}$, meaning that they derived from preexisting biliary cells, further confirming that DRs expand from the biliary tree (Figure 3A). Furthermore, as already described in CDE livers, YFP expression is also found in a limited number of hepatocytes that have differentiated from biliary/DR cells. $^{22}$ As seen on 2D liver slides, one-third of DR-derived $\mathrm{YFP}^{+}$hepatocytes were engaged in the junctions (ie, $\mathrm{YFP}^{+}$ hepatocytes with a ceacam- $1^{+}$apical pole in contact with mucin- ${ }^{+}$DR cells) (Figure 3, B, D, and E; see also Supplemental Figure S1 for schematic representation). Another third of DR-derived hepatocytes were observed directly adjacent to cells forming the junction (Figure 3, C and $\mathrm{E}$ ), and one-third were observed without any contact with junctions (Figure 3, D and E). The last third were not topographically related to a junction herein. However, they might be connected to a duct, and further three-dimensional analysis will better define this contribution. Nevertheless, these data further confirm that DRs expand from biliary epithelium to establish new junctions with canaliculi. They also interestingly suggest that the few hepatocytes in CDE livers that
A
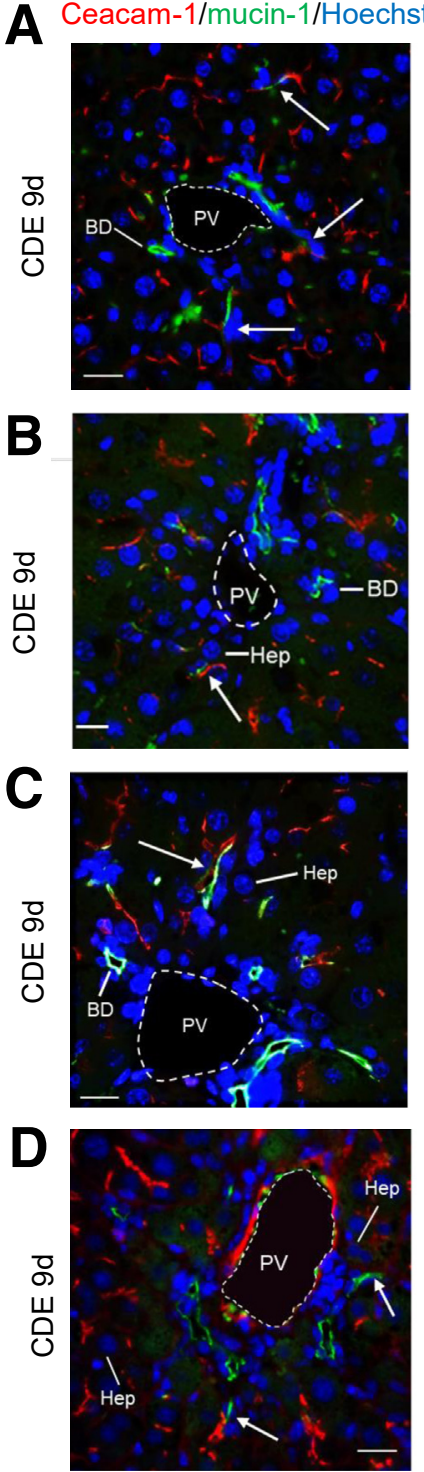

YFP
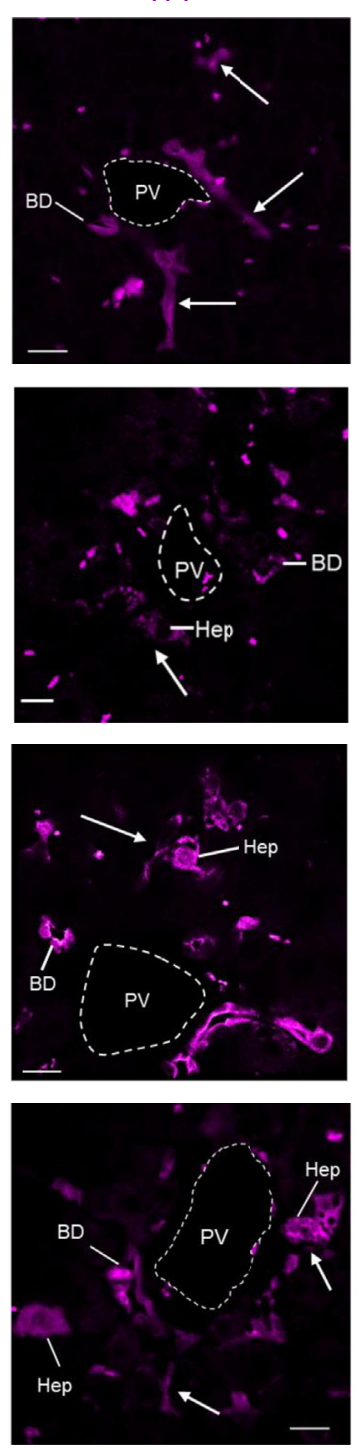

Merge
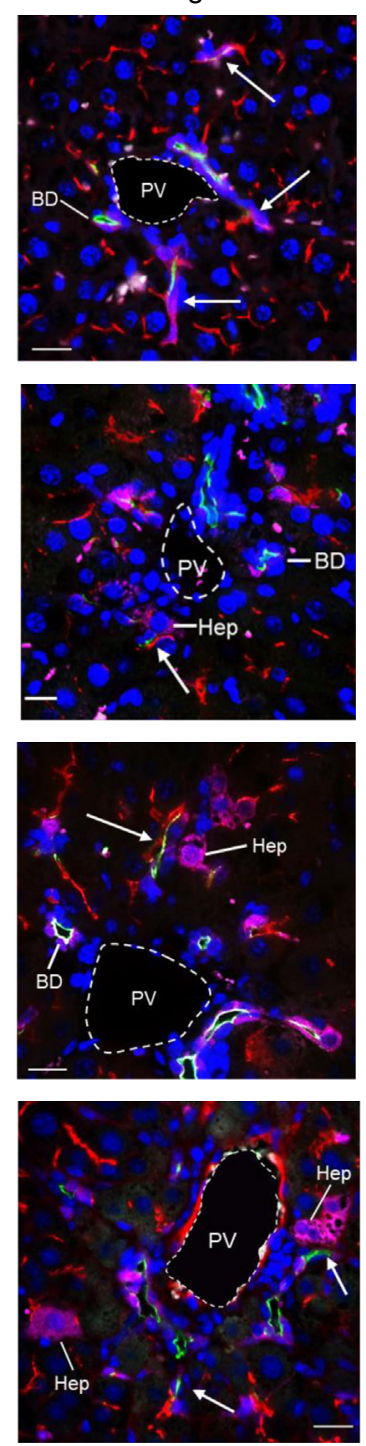

E

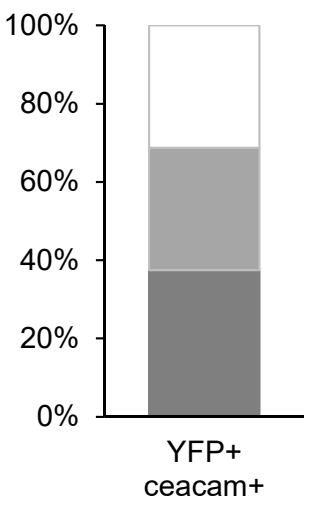

$\square$ No topographical relation with the junction

Adjacent to a cell engaged in the junction

Engaged in the junction

Figure 3 Ductular reaction-derived hepatocytes (Heps) are located close to hepatobiliary junctions. A-D: Liver sections from osteopontin-iCreER ${ }^{T 2}$; Rosa26YFP mice fed 9 days (9d) of choline-deficient ethionine-supplemented (CDE) regimen were costained with ceacam-1 (red), mucin-1 (green), and YFP (magenta). Hoechst was used to stain the nuclei (blue). Arrows indicate hepatobiliary junctions. E: Percentage of YFP ${ }^{+}$hepatocytes with a ceacam- $1^{+}$pole that were observed in contact with a mucin-1 $1^{+}$cell (engaged in the junction), in contact with a cell at a ceacam-1-mucin- 1 junction (adjacent to a cell engaged in the junction), or without any close contact with a junction (no topographic relation with the junction). A total of 4 mice, 12 liver slices, and $16 \mathrm{YFP}^{+}$hepatocyte(s) were analyzed. Scale bars $=20 \mu \mathrm{m}(\mathbf{A}-\mathbf{D})$. BD, bile duct; PV, portal vein. 

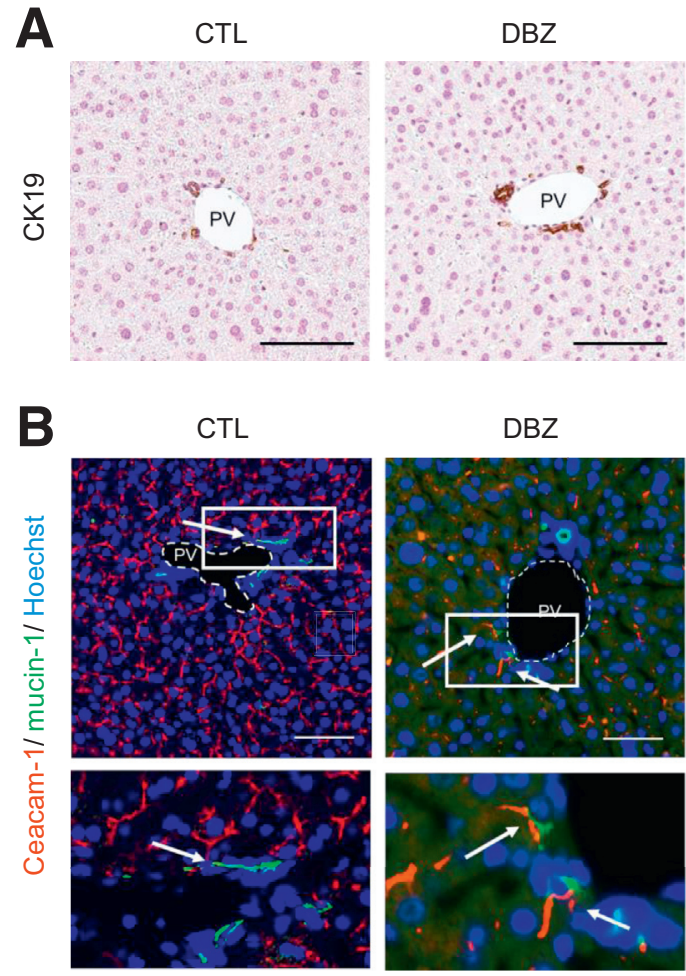

D

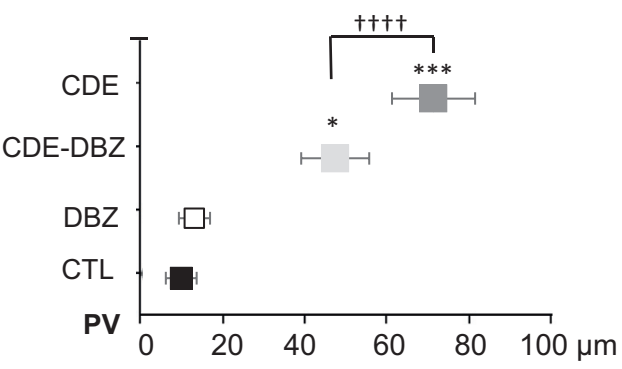

CDE

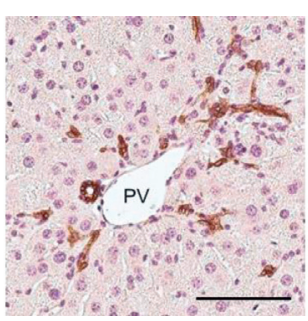

CDE
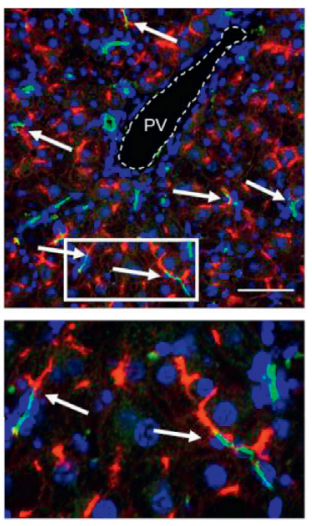

CDE - DBZ
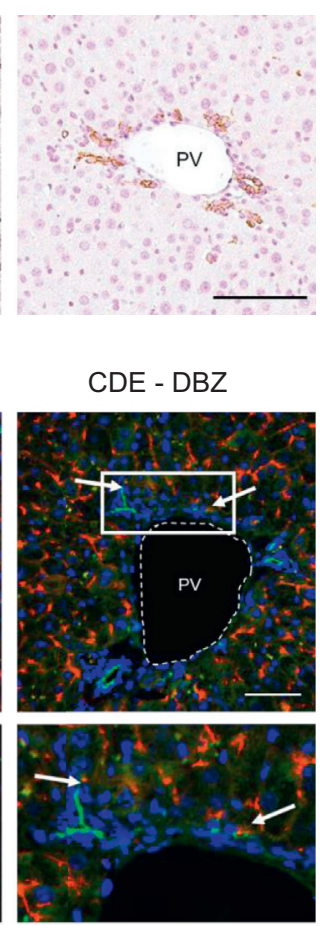

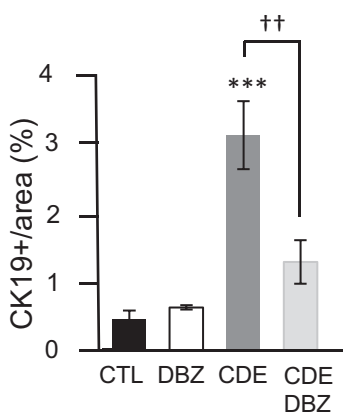

C

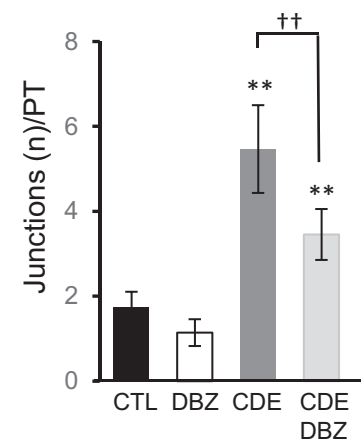

Figure 4 Ductular reaction (DR) inhibition correlates with decreased number of duct-canaliculi junctions in choline-deficient ethionine-supplemented (CDE) livers. A: Liver sections from mice receiving chow diet [control (CTL)], chow diet with dibenzazepine treatment (DBZ), CDE diet for 14 days (CDE), and CDE diet for 14 days in combination with daily DBZ treatment (CDE-DBZ) were stained with cytokeratin 19 (CK19). Morphometrical quantification of the area occupied by ${\mathrm{CK} 19^{+}}^{+}$cells in livers confirms invasive DR on CDE diet and reduction of CDE-induced DR extent with DBZ treatment. B: Liver sections from the same mice were costained with ceacam-1 (red), mucin-1 (green), and Hoechst (blue). White arrows indicate caecam-1/mucin- 1 junctions. Boxed areas are shown at higher magnification below. $\mathbf{C}$ and $\mathbf{D}$ : These liver sections were used to quantify the number of junctions (white arrows from $\mathbf{B}$ ) per portal vein $(\mathrm{PV} ; \mathbf{C})$ and to measure the distance between the junctions and the closest portal vein (D). Significance was calculated compared with controls, except when indicated. Data are expressed as means \pm SEM (A, C, and D). $n=3-5$ mice per group (A); $n=4-5$ mice per group (C and $\mathbf{D}) .{ }^{*} P<0.05$, ${ }^{* *} P<0.01$, and ${ }^{* * *} P<0.001$ versus control; ${ }^{\dagger \dagger} P<0.01,{ }^{\dagger \dagger \dagger \dagger} P<0.0001$. Scale bars $=100 \mu \mathrm{m}$ (A and B). PT, portal tract.

differentiate from DR cells may be located in the close vicinity of the neoformed hepatobiliary junctions.

\section{DR Inhibition Correlates with Reduced Number of DR- Canaliculi Junctions}

DBZ, an inhibitor of Notch signaling shown to decrease DR in other mouse models of liver injury, ${ }^{31,38}$ was then administered to CDE-fed mice. DBZ treatment significantly reduced DR extent in CDE mice (Figure 4A). This resulted in a reduced number of hepatobiliary junctions compared with untreated CDE livers (Figure 4, B and C). Moreover, these junctions were found less deep into the lobule when CDE mice were treated with DBZ (Figure 4D). Thus, reduction of CDE-induced DR extent correlates with reduced morphologic DR-canalicular junctions, consistent with a role of DR in preserving or repairing a morphologic link between hepatocyte and duct lumens.
No New Ductular-Canalicular Junctions Are Established after Biliary Obstructive Cholestasis

Livers from DDC-fed and BDL mice were evaluated to investigate whether DR participates in new hepatobiliary junctions in models of intrahepatic and extrahepatic bile duct obstruction, respectively. BDL surgery and DDC feeding both induced DR confined to the portal mesenchyme and forming pseudoductular structures, contrasting with the invasive CDE-induced DR pattern (Figure 5A). After both BDL and DDC, the number of hepatobiliary junctions did not significantly vary compared with controls, as assessed by double staining with biliary apical mucin and hepatocyte canalicular ceacam (Figure 5, B and C). Moreover, like in controls, the few observed junctions were in the vicinity of the limiting plate (Figure 5B). These data show that obstructive cholestasis in BDL and DDC does not foster novel hepatobiliary connections. 

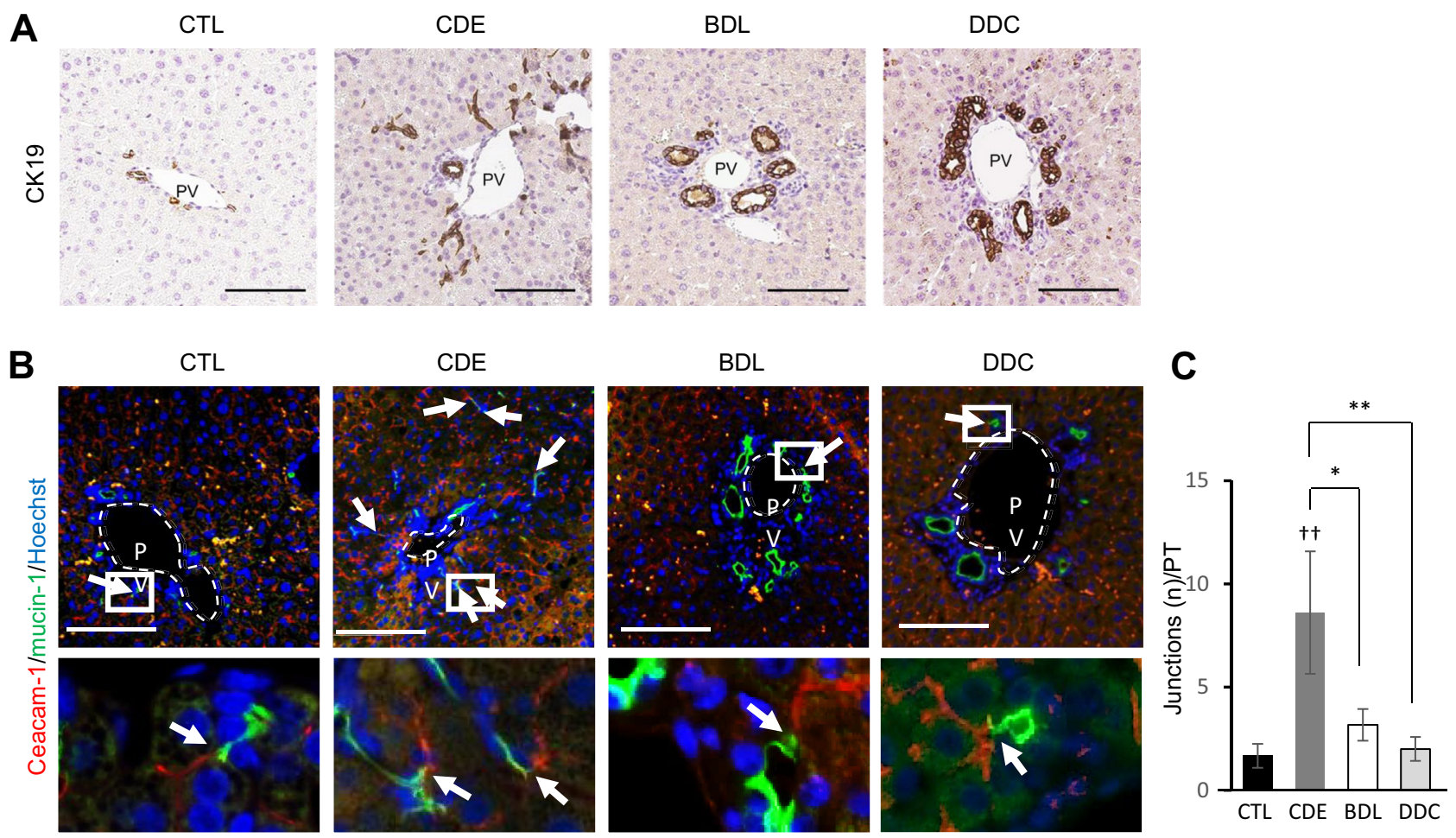

Figure 5 No novel ductular-canalicular junctions are established on diethoxycarbonyl-1,4-dihydrocollidine (DDC) and bile duct ligation (BDL) biliary damage. A and B: Liver sections from mice fed control diet (CTL), mice fed 9 days of choline-deficient ethionine-supplemented (CDE) regimen (CDE), mice fed 9 days after BDL surgery, or mice receiving 9 days of DDC diet (DDC) were stained for cytokeratin 19 (CK19; A) and costained with ceacam-1 (red), mucin-1 (green), and Hoechst (blue; B). Boxed areas are shown at higher magnification below. C: These liver sections were used to quantify the number of junctions (arrows) per portal vein (PV). Significance was calculated compared with controls, except when specified. Data are expressed as means \pm SD (C). $n=$ 3-5 mice per group (C). ${ }^{\star} P<0.05,{ }^{*} P<0.01 ;{ }^{\dagger \dagger} P<0.01$ versus control. Scale bars $=100 \mu \mathrm{m}(\mathbf{A}$ and $\mathbf{B})$. PT, portal tract.

Invasive DRs Establish New Junctions with Intralobular Canaliculi in Human Disorders Affecting Predominantly Hepatocytes

The ductular-canalicular junctions in human liver disorders were studied using double immunostaining with biliary CK19 and canalicular CD10. Normal human portal tracts showed $\mathrm{CK} 19^{+}$bile ducts, with no or few bile ductules, and $\mathrm{CoH}$ defined as the junction between $\mathrm{CK} 19^{+}$cells and $\mathrm{CD} 10^{+}$ canaliculi of periportal hepatocytes (Figure 6A). Each PT was analyzed individually, DR evalutated on the basis of CK19 staining, and each portal tract was classified as follows: i) normal, when normal BD but no DR was seen; ii) noninvasive, when the number of $\mathrm{CK} 19^{+}$biliary structures was increased and constrained to portal mesenchyme, comparable to BDL and DDC models; iii) minimally invasive, which referred to an increased number of $\mathrm{CK} 19^{+}$cells found outside the border of the portal mesenchyme; and iv) invasive, when CK $19^{+}$cells were observed outside the portal mesenchyme and expanded into the parenchyma, as seen in the CDE model (Figure 6A). The noninvasive DR phenotype was largely observed in all patients with predominant biliary diseases (eg, primary sclerosing cholangitis, primary biliary cholangitis, and biliary obstruction) and less strikingly in patients with hepatocellular dysfunctions (eg, drug-induced liver injury, hepatitis, or nonalcoholic steatohepatitis) (Table 1). The minimally invasive phenotype was not specific for hepatocellular or biliary liver disorders, whereas the invasive type was clearly observed in cases with hepatocellular damage but not in livers of patients with biliary disorders. The average number of junctions observed per portal area showing noninvasive DR within a liver sample had a tendency to decrease compared with controls, however not significantly (Figure 6B). In contrast, there was a higher average number of junctions per PT exhibiting invasive DR (mean, approximately 2 for minimally invasive DR and $>4$ for invasive DR compared with $<1$ in normal PT) (Figure 6B). These junctions were located in the parenchyma at a mean distance of approximatively 30 and 60 $\mu \mathrm{m}$, respectively, from the edge of the portal mesenchyme, whereas in normal PT and PT exhibiting noninvasive DR, junctions were found within $20 \mu \mathrm{m}$ from the edge of the mesenchyme (Figure 6C). These observations show that invasive DR, mostly associated with hepatocellular injury, establishes de novo junctions with canaliculi inside the parenchyma in humans, as in rodent models.

\section{Discussion}

Ductular response is encountered in almost all chronic and severe liver diseases in humans, but its physiological role in liver repair is still not well understood. To explore DR, several mouse models have been developed and used 


\section{A}

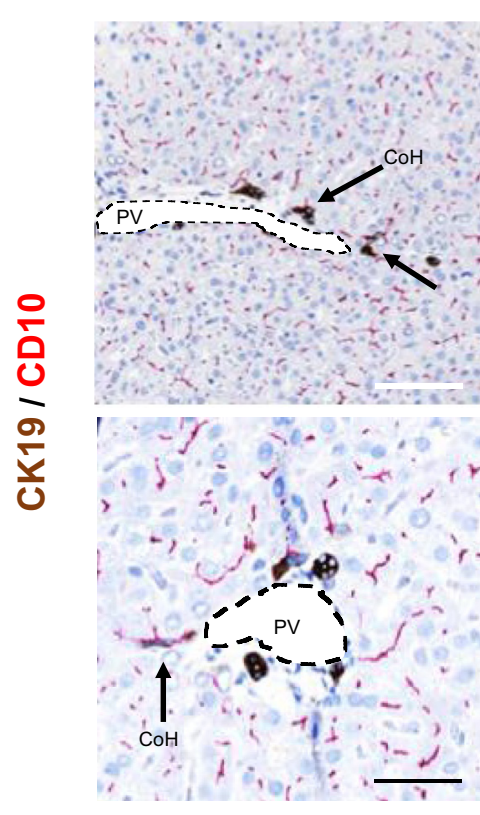

Non invasive

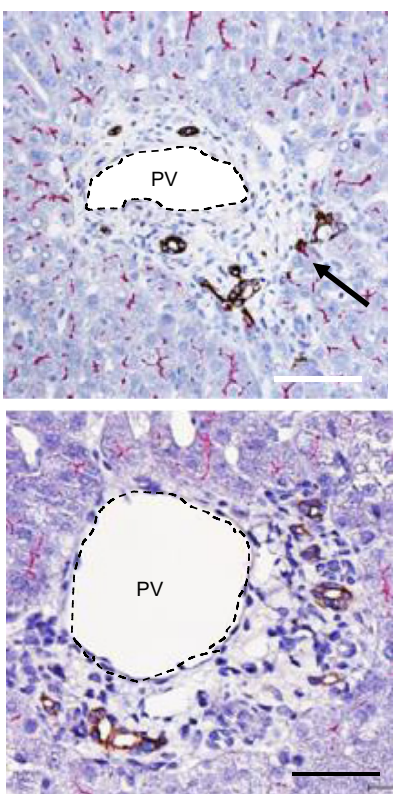

Minimal invasive

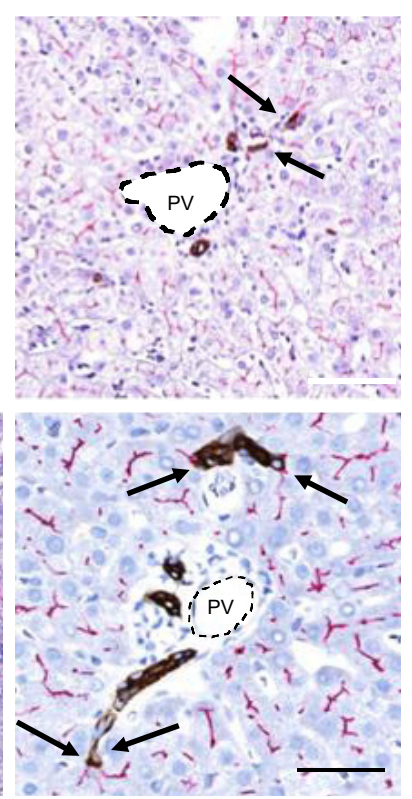

Invasive

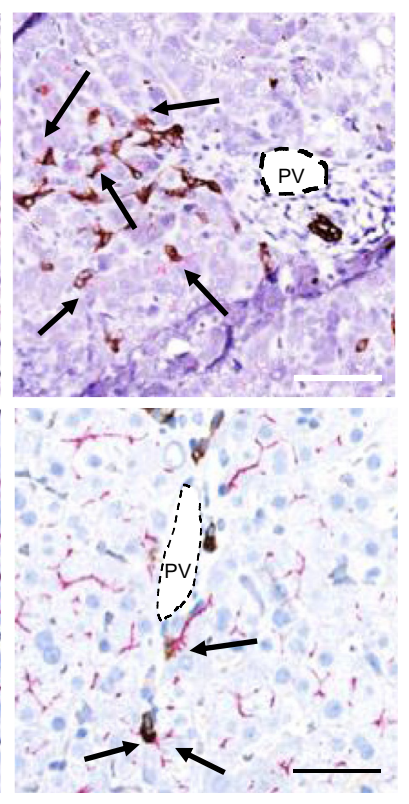

B

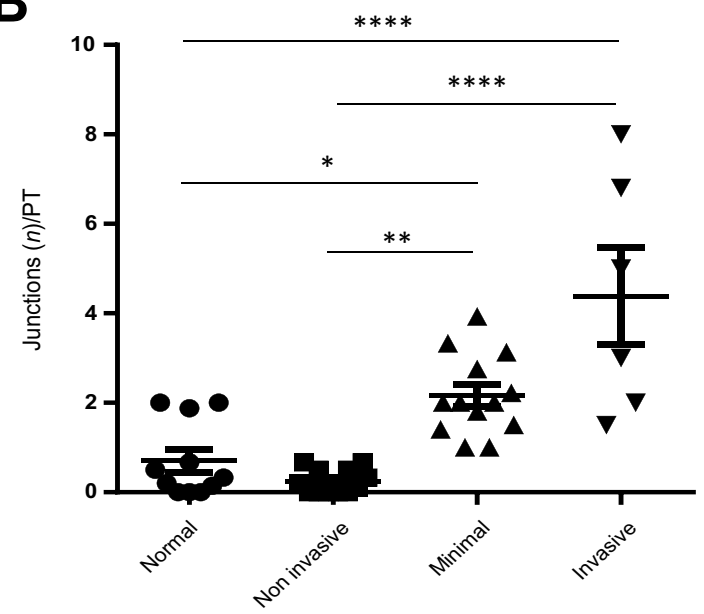

C

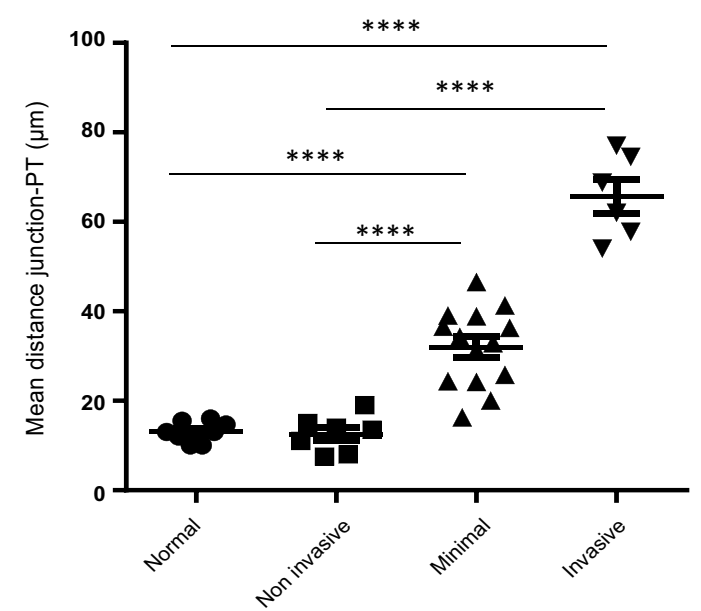

Figure 6 Invasive ductular reactions (DRs) establish new junctions with lobular canaliculi in human disorders affecting predominantly hepatocytes. A: Human liver sections from patients with various hepatic disorders were costained for cytokeratin 19 (CK19) and CD10. Arrows point toward CK19/CD10 junctions. B and C: These liver sections were used to quantify the number of CK19-CD10 junctions (arrows in A) per portal tract (PT; B) and to measure the distance between the junctions and the border of the portal mesenchyma as the mean per portal tract per case (C). When at least one junction around a PT was seen $>80 \mu \mathrm{m}$ from the border of the portal mesenchyma, the associated DR was classified as invasive; when junctions were observed between 20 and $80 \mu \mathrm{m}$, DR was categorized as minimally invasive; and when junctions were seen $<20 \mu \mathrm{m}$ or within the portal mesenchyma, DR was classified as noninvasive. Significance was calculated compared with the mean. ${ }^{*} P<0.05,{ }^{*} P<0.01$, and ${ }^{*} * * P<0.0001$. Scale bars: $100 \mu \mathrm{m}(\mathbf{A}$, top row); $50 \mu \mathrm{m}(\mathbf{A}$, bottom row). $\mathrm{CoH}$, canal of Hering; PV, portal vein.

interchangeably. However, accumulative data support that DR differs, depending on the type of the injury and thereby of the model used. ${ }^{10,11,21}$ Therefore, DR function should be addressed in the context of the underlying injury. In this study, we investigated the hepatobiliary junctions operated by DR in experimental models as well as in human samples of liver diseases representative of both hepatocellular damage and biliary obstructive injury. The CDE mouse model was used to mimic hepatocellular diseases and the DDC and BDL for biliary chronic disease.
Recent work reported that CDE-induced DR organized as tubular structures connected to the preexisting bile ducts. ${ }^{10,14}$ Accordingly, plastination of the bile duct system revealed a denser intrahepatic biliary network in CDE livers. ${ }^{12}$ In line with these reports, we show herein that DR expands in the CDE-damaged parenchyma as polarized biliary cells expressing the machinery needed to sense and modify bile. We further show that those biliary ramifications form de novo junctions with the canalicular network, thus establishing a solution of continuity between the primary site of bile secretion 
Table 1 Number of Individual PTs Exhibiting the Different DR Phenotype Relative to the Human Disease Etiology

\begin{tabular}{|c|c|c|c|c|}
\hline Human disease etiology & Normal & Noninvasive & Minimally invasive & Invasive \\
\hline PSC, $n$ & 0 & 13 & 5 & 0 \\
\hline $\mathrm{PBC}, n$ & 2 & 17 & 5 & 0 \\
\hline (N)ASH, $n$ & 14 & 6 & 20 & 2 \\
\hline Hepatocellular damage, $n$ & 12 & 10 & 33 & 34 \\
\hline
\end{tabular}

Each PT was analyzed individually, and the associated DR phenotype was classified as follows: i) normal, when normal cytokeratin 19-positive (CK19+) bile duct but no DR was seen; ii) noninvasive, when the number of $\mathrm{CK}_{1} 9^{+}$cells increased but remained constrained to portal mesenchyme; iii) minimally invasive, when $\mathrm{CK}_{1} 9^{+}$cells were found outside the border of the portal mesenchyme; and iv) invasive, when $\mathrm{CK}_{1} 9^{+}$cells were observed deep into the parenchyma. A total of 18 PTs were analyzed for PSC, 24 for PBC, 33 for biliary obstruction, 42 for NASH, and 89 for drug-induced liver injury and hepatitis.

DR, ductular reaction; (N)ASH, (non)alcoholic steatohepatitis; PBC, primary biliary cholangitis; PSC, primary sclerosing cholangitis; PT, portal tract.

(canaliculi) and the bile duct drainage system. 2D examinations as well as Z-stack imaging of CDE livers show topographical connection between the most proximal extremities of DR and canaliculi. Thus, cells at the extremity of the DR must be capable of forming tight cellular interactions with hepatocytes. In a normal liver, this unique property is the prerogative of the cells of the CoH. ${ }^{9,39}$ As shown herein, invasive DR generates new and more numerous $\mathrm{CoH}$ and relocates them inside the parenchyma. Yet, the molecular nature of the cell/ cell connection between cholangiocytes and hepatocytes, whether occurring at the physiological $\mathrm{CoH}$ or at the extremity of the DR, still remains to be identified. Previous data, by us and others, demonstrated that (some) DR cells differentiate into hepatocytes. ${ }^{21,22,25,40}$ Herein, we showed that approximately two-thirds of hepatocytic differentiation of DR cells, analyzed by $2 \mathrm{D}$ observations, occurs at the close vicinity of the neoformed junctions, supporting the proposed idea that DR in CDE livers may generate asymmetric hepatocytes able to link DR/biliary cells on the one side with preexisting hepatocytes on the other side to establish a continuum. ${ }^{29}$ Thus, the low number of DR-derived hepatocytes reported by many groups in this model ${ }^{21,22,25,40}$ could correspond to the generation of a specific subpopulation able to establish hepatobiliary connection. Therefore, although apparently insignificant in terms of parenchymal regeneration, the process maintains a morphologic link between hepatocytes and bile ducts and may physiologically benefit to intralobular bile drainage. This DR role in bile drainage is supported by the recent study of PradhanSundd et al, ${ }^{41}$ released while writing this article, in which the authors used quantitative liver intravital microscopy to show recovery of the hepatic canaliculi integrity and function after establishment of DR on prolonged CDE injury. This finding goes in the same direction as our above observations that the reduction of DR in CDE-injured mice may impair the reparative process. Future studies using in vivo imaging and digital reconstruction of three-dimensional analysis would be needed to provide even deeper insight into the spatiotemporal remodeling and functional importance of CDE-associated DR.

More importantly, rearrangement of the bile network on CDE injury differs from the biliary plasticity observed after biliary obstructive injury. Bile duct obstruction by surgical ligation in BDL or by porphyria plugs in DDC does not cause infiltration of DR into the parenchyma; instead, a denser mesh of interlobular ducts around the portal vein is formed. ${ }^{12,14,42}$ In these models, bile retention in bile ducts stimulates the proliferation of cholangiocytes. ${ }^{43}$ In BDL, this causes first corrugation of the luminal duct surface, then elongation and branching of interlobular ducts, leading to a fivefold increase of the ductal surface within the portal mesenchyme. ${ }^{14}$ In DDC-induced mechanical duct obstruction, this drives dilatation of intrahepatic ducts. ${ }^{42}$ The increase in the surface of the interphase between bile and cholangiocytes favors bile resorption, whereas duct elongation in BDL and ductal dilatation in DDC attempt to overcome bile flow obstruction. The number of hepatobiliary junctions remains unchanged during the course of biliary obstructive BDL and DDC injury (Figure 5). ${ }^{14}$ In contrast, in the CDE model, bile duct obstruction is not the issue. Rather, hepatocellular injury will cause disruption of the canalicular continuity. CDE-induced DR invades into the parenchyma and connects proximal canaliculi with preexisting ducts to maintain morphologic continuity between hepatocytes and the biliary tree. In a similar manner, invasive DR, seen in livers of patients with disorders that predominantly damage hepatocytes, established several new junctions with canaliculi. In contrast, the noninvasive DR confined to portal mesenchyme, found in livers of patients with biliary diseases, did not. Our findings provide a demonstration of the contribution of invasive DR to operate hepatobiliary junctions supposedly for biliary drainage.

Finally, the molecular mechanisms driving DR proliferation, migration, and differentiation remain poorly understood. Works during the past decade support a key role of the pathologic-specific surrounding niche in shaping DR. ${ }^{44}$ In the CDE injury model, spatially intimate correlation of DR with the extracellular matrix has been precisely described, with matrix components, such as laminin-basal membrane, shown to contribute to DR biliary phenotype maintenance. ${ }^{22,36,45,46}$ The Notch signaling pathway has been also identified as driving biliary fate ${ }^{47-49}$ and promoting DR expansion in the DDC and methionine-choline-deficient mouse models. ${ }^{31,38}$ Herein, we showed that inhibition of Notch signaling significantly reduced the extent of CDE-induced DR, supporting Notch relevance in regulating biliary DR expansion in the CDE injury model as well. In addition, the inflammatory response, with secreted 
cytokines, such as tumor necrosis factor- $\alpha$, and the receptor tumor necrosis factor-like weak inducer of apoptosis, was described as key modulators of DR in the CDE model. ${ }^{27,50-52}$ In the light of our data, it is tempting to speculate that signals emanating from sensing of the modifications of bile (flow and composition) and bile acid pool are also involved in DR modulation. Indeed, CDE injury modifies in quantity and composition the bile in contact with the hepatocyte canalicular pole and the biliary epithelium. In support to a bile acid-driven remodeling, previous studies established a role for bile acid in modulating cholangiocyte proliferation through a mechanism involving secretin receptor. ${ }^{53}$ Furthermore, bile acids also function as potent signaling molecules that modulate key metabolism pathways and could play a role in the inflammasome and healing response. ${ }^{54-57}$ In that view, in the same injured liver, DR could function as biliary structures as well as differentiate into hepatocytes responding to the intricated signals from the closely injury-induced surrounding niche.

In conclusion, our findings demonstrate a hepatobiliary junctional role of the invasive form of DR. Next to bile duct remodeling and potentiality to generate new hepatocytes, this further highlights the remarkable cellular plasticity of cells of the ductular response. Increasing our understanding of injury-specific mechanisms and signals regulating DR will identify tools to manipulate the system and test the therapeutic impact on chronic liver diseases, including cholestatic pathologies.

\section{Acknowledgments}

We thank Prof. Yves Horsmans (St. Luc University Hospital, UCL, Brussels, Belgium), Prof. Jan G. Hengstler, Nachiket Vartak, and Amruta Damle-Vartak (Leibniz Research Centre for Working Environment and Human Factors, Dortmund, Germany) for fruitful discussion of the project and the data; Valerie Lebrun, Natacha Feza-Bingui, Boris Pirlot (Laboratory of Gastroenterology, Institute for Experimental and Clinical Research, UCLouvain, Brussels, Belgium), and Patrick Van Der Smissen (De Duve Institute, UCLouvain, Brussels, Belgium) for excellent technical assistance; Prof. Frederic Lemaigre (De Duve Institute, UCLouvain) for generating osteopontin-Cre mice and making them available for this study; and the Biobank of the Service of Clinical Pathology, Lausanne University Hospital (in charge: Nathalie Piazzon) for providing the human liver biopsies.

L.A.C. designed the study, conducted experiments, and analyzed data; R.M. conducted experiments and analyzed data; C.B. designed semiquantitative analysis; C.S. and A.S. conducted human stainings; N.V.H. initiated the project, developed and tested the methodological concepts; N.D.T. defined the hypothesis and intepreted the data; I.L. was the principle investigator, designed the experiment, secured the funding for the study, analyzed the data, and oversaw the writing of the manuscript; L.A.C. and I.L. wrote the original manuscript; all authors read and edited the manuscript.

\section{Supplemental Data}

Supplemental material for this article can be found at http://doi.org/10.1016/j.ajpath.2019.04.011.

\section{References}

1. Saxena R, Theise ND: Canals of Hering: recent insights and current knowledge. Semin Liver Dis 2004, 24:43-48

2. Roskams TA, Theise ND, Balabaud C, Bhagat G, Bhathal PS, Bioulac-sage P, Brunt EM, Crawford JM, Crosby HA, Desmet V, Finegold MJ, Geller SA, Gouw ASH, Hytiroglou P, Knisely AS, Kojiro M, Lefkowitch JH, Nakanuma Y, Olynyk JK, Park YN, Portmann B, Saxena R, Scheuer PJ: Nomenclature of the finer branches of the biliary. Hepatology 2004, 39:1739-1745

3. Maroni L, Haibo B, Ray D, Zhou T, Wan Y, Meng F, Marzioni M, Alpini G: Functional and structural features of cholangiocytes in health and disease. Cell Mol Gastroenterol Hepatol 2015, 1:368-380

4. Han Y, Glaser S, Meng F, Francis H, Marzioni M, McDaniel K, Alvaro D, Venter J, Carpino G, Onori P, Gaudio E, Alpini G, Franchitto A: Recent advances in the morphological and functional heterogeneity of the biliary epithelium. Exp Biol Med 2013, 238: 549-565

5. Tabibian JH, Masyuk AI, Masyuk TV, O'Hara SP, LaRusso NF: Physiology of cholangiocytes. Compr Physiol 2013, 3:541-565

6. Trauner M, Meier PJ, Boyer JL: Molecular pathogenesis of cholestasis. N Engl J Med 1998, 339:1217-1227

7. Hirschfield GM, Heathcote EJ, Gershwin ME: Pathogenesis of cholestatic liver disease and therapeutic approaches. Gastroenterology 2010, 139:1481-1496

8. Jansen PLM, Ghallab A, Vartak N, Reif R, Schaap FG, Hampe J, Hengstler JG: The ascending pathophysiology of cholestatic liver disease. Hepatology 2017, 65:722-738

9. Gouw ASH, Clouston AD, Theise ND: Ductular reactions in human liver: diversity at the interface. Hepatology 2011, 54:1853-1863

10. Kaneko K, Kamimoto K, Miyajima A, Itoh T: Adaptive remodeling of the biliary architecture underlies liver homeostasis. Hepatology 2015, 61:2056-2066

11. Köhn-Gaone J, Dwyer BJ, Grzelak CA, Miller G, Shackel NA, Ramm GA, McCaughan GW, Elsegood CL, Olynyk JK, TirnitzParker JEE: Divergent inflammatory, fibrogenic, and liver progenitor cell dynamics in two common mouse models of chronic liver injury. Am J Pathol 2016, 186:1762-1774

12. Clerbaux L-A, Van Hul N, Gouw ASH, Manco R, Español-Suñer R, Leclercq IA: Relevance of the CDE and DDC mouse models to study ductular reaction in chronic human liver diseases. Animal Models for Human Diseases. Edited by Ibeh B. InTech Open 2018

13. Alison M, Golding M, Lalani E-N, Sarraf C: Wound healing in the liver with particular reference to stem cells. Philos Trans R Soc London 1998, 353:877-894

14. Vartak N, Damle-Vartak A, Richter B, Dirsch O, Dahmen U, Hammad S, Hengstler JG: Cholestasis-induced adaptive remodeling of interlobular bile ducts. Hepatology 2016, 63:951-964

15. Theise ND, Saxena R, Portmann BC, Thung SN, Yee H, Chiriboga L, Kumar A, Crawford JM: The canals of Hering and hepatic stem cells in humans. Hepatology 1999, 30:1425-1433

16. Roskams T: Progenitor cell involvement in cirrhotic human liver diseases: from controversy to consensus. J Hepatol 2003, 39: 431-434 
17. Roskams TA, Libbrecht L, Desmet VJ: Progenitor cells in diseased human liver. Semin Liver Dis 2003, 23:385-396

18. Lu W-Y, Bird TG, Boulter L, Tsuchiya A, Cole AM, Hay T, Guest RV, Wojtacha D, Man TY, Mackinnon A, Ridgway RA, Kendall T, Williams MJ, Jamieson T, Raven A, Hay DC, Iredale JP, Clarke AR, Sansom OJ, Forbes SJ: Hepatic progenitor cells of biliary origin with liver repopulation capacity. Nat Cell Biol 2015, 17: 971-983

19. Raven A, Lu W-Y, Man TY, Ferreira-Gonzalez S, O’Duibhir E, Dwyer BJ, Thomson JP, Meehan RR, Bogorad R, Koteliansky V, Kotelevtsev Y, Ffrench-Constant C, Boulter L, Forbes SJ: Cholangiocytes act as facultative liver stem cells during impaired hepatocyte regeneration. Nature 2017, 547:350-354

20. He J, Lu H, Zou Q, Luo L: Regeneration of liver after extreme hepatocyte loss occurs mainly via biliary transdifferentiation in zebrafish. Gastroenterology 2014, 146:789-800.e8

21. Rodrigo-Torres D, Affò S, Coll M, Morales-Ibanez O, Millán C, Blaya D, Alvarez-Guaita A, Rentero C, Lozano JJ, Maestro MA, Solar M, Arroyo V, Caballería J, van Grunsven LA, Enrich C, Ginès P, Bataller R, Sancho-Bru P: The biliary epithelium gives rise to liver progenitor cells. Hepatology 2014, 60:1367-1377

22. Español-Suñer R, Carpentier R, Van Hul N, Legry V, Achouri Y, Cordi S, Jacquemin P, Lemaigre F, Leclercq IA: Liver progenitor cells yield functional hepatocytes in response to chronic liver injury in mice. Gastroenterology 2012, 143:1564-1575

23. Schaub JR, Malato Y, Gormond C, Willenbring H: Evidence against a stem cell origin of new hepatocytes in a common mouse model of chronic liver injury. Cell Rep 2014, 8:933-939

24. Tarlow BD, Finegold MJ, Grompe M: Clonal tracing of Sox9+ liver progenitors in mouse oval cell injury. Hepatology 2014, 60:278-289

25. Shin S, Upadhyay N, Greenbaum L, Kaestner K: Ablation of Foxl1 Cre-labeled hepatic progenitor cells and their descendants impairs recovery from liver injury. Gastroenterology 2015, 33:395-401

26. Akhurst B, Croager EJ, Farley-Roche CA, Ong JK, Dumble ML, Knight B, Yeoh GC: A modified choline-deficient, ethionine-supplemented diet protocol effectively induces oval cells in mouse liver. Hepatology 2001, 34:519-522

27. Verhulst S, Best J, Syn W-K, Reynaert H, Hellemans KH, Canbay A, Dolle L, van Grunsven LA: Infliximab and dexamethasone attenuate the ductular reaction in mice. Sci Rep 2016, 6:36586

28. Kuwahara R, Kofman AV, Landis CS, Swenson ES, Barendswaard E, Theise N: The hepatic stem cell niche: identification by labelretaining cell assay. Hepatology 2008, 47:1994-2002

29. Theise ND, Dollé L, Kuwahara R: Low hepatocyte repopulation from stem cells: a matter of hepatobiliary linkage not massive production. Gastroenterology 2013, 145:253-254

30. Desmet VJ: Ductal plates in hepatic ductular reactions: hypothesis and implications, I: types of ductular reaction reconsidered. Virchows Arch 2011, 458:251-259

31. Fiorotto R, Raizner A, Morell CM, Torsello B, Scirpo R, Fabris L, Spirli C, Strazzabosco M: Notch signaling regulates tubular morphogenesis during repair from biliary damage in mice. J Hepatol 2013, 59:124-130

32. Mu X, Español-suñer R, Mederacke I, Affò S, Manco R, Sempoux C, Lemaigre FP, Adili A, Yuan D, Weber A, Unger K, Heikenwälder M, Leclercq IA, Schwabe RF: Hepatocellular carcinoma originates from hepatocytes and not from the progenitor/biliary compartment. J Clin Invest 2015, 125:3891-3903

33. Van Hul N, Abarca-Quinones J, Sempoux C, Horsmans Y, Leclercq IA: Relation between liver progenitor cell expansion and extracellular matrix deposition in a CDE-induced murine model of chronic liver injury. Hepatology 2009, 49:1625-1635

34. Lenzi R, Liu M, Tarsetti F, Slott P, Alpini G, Zhai W, Paronetto F, Lenzen R, Tavolini N: Histogenesis of bile duct-like cells proliferating during ethionine hepatocarcinogenesis: evidence for a biliary epithelial nature of oval cells. Lab Invest 1992, 66:390-402
35. Miyao M, Ozeki M, Abiru H, Manabe S, Kotani H, Tsuruyama T, Tamaki K: Bile canalicular abnormalities in the early phase of a mouse model of sclerosing cholangitis. Dig Liver Dis 2013, 45:216-225

36. Carpentier R, Español-Suñer R, Van Hul N, Kopp JL, Beaudry J-B, Cordi S, Antoniou A, Raynaud P, Lepreux S, Jacquemin P, Leclercq IA, Sander M, Lemaigre FP: Embryonic ductal plate cells give rise to cholangiocytes, periportal hepatocytes and adult liver progenitor cells. Gastroenterology 2011, 141:1432-1438

37. Manco R, Clerbaux L-A, Verhulst S, Nader MB, Sempoux C, Ambroise J, Bearzatto B, Gala JL, Horsmans Y, van Grunsven L, Desdouets C, Leclercq I: Reactive cholangiocytes differentiate into proliferative hepatocytes with efficient DNA repair in mice with chronic liver injury. J Hepatol 2019, 70:1180-1191

38. Morell C, Fiorotto R, Meroni M, Raizner A, Torsello B, Cadamuro M, Spagnuolo G, Kaffe E, Sutti S, Albano E, Strazzabosco M: Notch signaling and progenitor/ductular reaction in steatohepatitis. PLoS One 2017, 12:e0187384

39. Miyajima A, Tanaka M, Itoh T: Stem/progenitor cells in liver development, homeostasis, regeneration, and reprogramming. Cell Stem Cell 2014, 14:561-574

40. Furuyama K, Kawaguchi Y, Akiyama H, Horiguchi M, Kodama S, Kuhara T, Hosokawa S, Elbahrawy A, Soeda T, Koizumi M, Masui T, Kawaguchi M, Takaori K, Doi R, Nishi E, Kakinoki R, Deng JM, Behringer RR, Nakamura T, Uemoto S: Continuous cell supply from a Sox9-expressing progenitor zone in adult liver, exocrine pancreas and intestine. Nat Genet 2011, 43:34-41

41. Pradhan-Sundd T, Vats R, Russell JM, Singh S, Michael AA, Molina L, Kakar S, Cornuet P, Poddar M, Watkins SC, NejakBowen KN, Monga SP, Sundd P: Dysregulated bile transporters and impaired tight junctions during chronic liver injury in mice. Gastroenterology 2018, 155:1218-1232.e24

42. Fickert P, Stöger U, Fuchsbichler A, Moustafa T, Marschall H-U, Weiglein AH, Tsybrovskyy O, Jaeschke H, Zatloukal K, Denk H, Trauner M: A new xenobiotic-induced mouse model of sclerosing cholangitis and biliary fibrosis. Am J Pathol 2007, 171:525-536

43. Glaser S, Gaudio E, Rao A, Pierce LM, Onori P, Franchitto A, Francis HL, Dostal DE, Venter JK, DeMorrow S, Mancinelli R, Carpino G, Alvaro D, Kopriva SE, Savage JM, Alpini GD: Morphological and functional heterogeneity of the mouse intrahepatic biliary epithelium. Lab Invest 2009, 89:456-469

44. Manco R, Leclercq IA, Clerbaux L-A: Liver regeneration: different sub-populations of parenchymal cells at play choreographed by an injury-specific microenvironment. Int J Mol Sci 2018, 19:4115

45. Van Hul N, Lanthier N, Español Suñer R, Abarca Quinones J, Van Rooijen N, Leclercq I: Kupffer cells influence parenchymal invasion and phenotypic orientation, but not the proliferation, of liver progenitor cells in a murine model of liver injury. Am J Pathol 2011, 179:1839-1850

46. Lorenzini S, Bird TG, Boulter L, Bellamy C, Aucott R, Clayton E, Andreone P, Bernardi M: Characterisation of a stereotypical cellular and extracellular adult liver progenitor cell niche in rodents and diseased human liver. Gut 2010, 59:645-654

47. Zong Y, Panikkar A, Xu J, Antoniou A, Raynaud P, Lemaigre F, Stanger BZ: Notch signaling controls liver development by regulating biliary differentiation. Development 2009, 1739:1727-1739

48. Boulter L, Govaere O, Bird T, Radulescu S, Ramachandran P, Pellicoro A, Ridgway RA, Seo SS, Spee B, Van Rooijen N, Sansom OJ, Iredale JP, Lowell S, Roskams T, Forbes SJ: Macrophage derived Wnt signalling opposes Notch signalling in a Numb mediated manner to specify HPC fate in chronic liver disease in human and mouse. Nat Med 2012, 18:572-579

49. Clerbaux L-A, Manco R, Leclercq IA: Upstream regulators of hepatic Wnt/b-catenin activity control liver metabolic zonation, development, and regeneration. Hepatology 2016, 64:1361-1363

50. Jakubowski A, Ambrose C, Parr M, Lincecum JM, Wang MZ, Zheng TS, Browning B, Michaelson JS, Baestcher M, Wang B, 
Bissell DM, Burkly LC: TWEAK induces liver progenitor cell proliferation. J Clin Invest 2005, 115:2330-2340

51. Tirnitz-parker JEE, Viebahn CS, Jakubowski A, Klopcic BRS, Olynyk JK, Yeoh GCT, Knight B: Tumor necrosis factor-like weak inducer of apoptosis is a mitogen for liver progenitor cells. Hepatology 2010, 52:291-302

52. Viebahn CS, Yeoh GC: What fires prometheus? the link between inflammation and regeneration following chronic liver injury. Int J Biochem Cell Biol 2008, 40:855-873

53. Glaser S, Lam IP, Franchitto A, Gaudio E, Onori P, Chow BK, Wise C, Kopriva S, Venter J, White M, Ueno Y, Dostal D, Carpino G, Mancinelli R, Demorrow S, Francis H, Alpini G:
Knockout of secretin receptor reduces large cholangiocyte hyperplasia in mice with extrahepatic cholestasis induced by bile duct ligation. Hepatology 2010, 52:204-214

54. Hylemon PB, Zhou H, Pandak WM, Ren S, Gil G, Dent P: Bile acids as regulatory molecules. J Lipid Res 2009, 50:1509-1520

55. Xia X, Francis H, Glaser S, Alpini G, LeSage G: Bile acid interactions with cholangiocytes. World J Gastroenterol 2006, 12: 3553-3563

56. Jones H, Alpini G, Francis H: Bile acid signaling and biliary functions. Acta Pharm Sin B 2015, 5:123-128

57. Fickert $\mathrm{P}$, Wagner M: Review biliary bile acids in hepatobiliary injury: what is the link? J Hepatol 2017, 67:619-631 